\title{
Geo-Statistical Assessment of Spatial Variability of Soil Water-Holding Capacity for Optimal Irrigation Under Semi-Arid Vertisols in South India
}

\section{RAMACHANDRAN J ( $\nabla$ eeesurya.tnau@gmail.com )}

Tamil Nadu Agricultural University

\section{R. Lalitha}

Tamil Nadu Agricultural University

S.Vallal Kannan

Tamil Nadu Agricultural University

K. Sivasubramanian

Tamil Nadu Agricultural University

\section{G.R.Maruthi Sankar}

Central Research Institute for Dryland Agriculture

\section{Research Article}

Keywords: Available water holding capacity, Field capacity, Wilting point, Soil texture, Geostatistics, Irrigation, Semivariogram, Spatial autocorrelation, Vertisols

Posted Date: February 7th, 2022

DOI: https://doi.org/10.21203/rs.3.rs-1295672/v1

License: (c) (1) This work is licensed under a Creative Commons Attribution 4.0 International License. Read Full License 


\title{
Geo-Statistical Assessment of Spatial Variability of Soil Water-holding
}

\section{Capacity for Optimal Irrigation under Semi-arid Vertisols in South India}

\author{
J.Ramachandran', R.Lalitha ${ }^{2}$, S.Vallal Kannan ${ }^{3}$, K.Sivasubramanian ${ }^{4}$ and
}

\section{G.R.Maruthi Sankar 5}

${ }^{1}$ Teaching Assistant, Department of Agricultural Engineering, Agricultural College and Research Institute, Tamil Nadu Agricultural University (TNAU), Madurai-625104, Tamil Nadu, India;

${ }^{2}$ Professor and Head, Department of Soil and Water Conservation Engineering, Agricultural Engineering College and Research Institute, TNAU, Kumulur-621712, Trichy, Tamil Nadu, India;

${ }^{3}$ Assistant Professor (Agronomy), Department of Irrigation and Drainage Engineering, Agricultural Engineering College and Research Institute, TNAU, Kumulur-621712, Trichy, Tamil Nadu, India; and

${ }^{4}$ Associate Professor (ENS), Office of Controller of Examination, TNAU, Coimbatore-641003, Tamil Nadu, India.

${ }^{5}$ Ex-Principal Scientist (Agricultural Statistics), ICAR-CRIDA, Hyderabad-500059, Telangana, India Corresponding author: J.Ramachandran $\quad$ E-mail:eeesurya.tnau@gmail.com

Abstract: Based on a field survey conducted in Lalgudi block, Tiruchirapalli district, Tamil Nadu, India, details pertaining to the crops grown, cropping pattern, land utilization and soil samples were collected from 20 locations under 7 different soil textures of semi-arid vertisols. Using the data, efficient geostatistical models have been explored to study the spatial variation of irrigation water requirement of paddy, sugarcane and banana grown in the study area. Field capacity and wilting point are two major soil physical properties that would influence the available plant water. These parameters were estimated with the pressure plate apparatus using soil samples collected in the block. Soil texture-wise assessment was made with regard to the field capacity, wilting point and soil water holding capacity based on the observations. The locations of Lalgudi block were grouped into three categories based on the mean and standard deviation of available water holding capacity, field capacity and wilting point parameters and were statistically assessed. The groups were made by considering the 
locations with values of a parameter lying under (i) < (Mean - SD); (ii) (Mean - SD) to $($ Mean + SD); and (iii) $>($ Mean + SD) limits. Geostatistics were applied for identifying the best interpolation method in order to acquire the spatial map of the available water holding capacity. An initial data exploration indicated about non-normal distribution of the available water holding capacity. Accordingly, log-transformation was made before kriging technique was used for the data. Ordinary kriging and Disjunctive kriging were explored with six models viz., Circular, Spherical, Exponential, Gaussian, Penta-spherical and Sine-Hole effect models and were used for spatial prediction. An estimate of Root Mean Square Error (RMSE) based onthe six models ranged from 2.1 to 2.5 for available water holding capacity parameter. The cross validation statistics indicated that Sine-Hole effect model with disjunctive kriging of available water holding capacity was superior for interpolation with minimum value of RMSE and moderate spatial dependency. The Sine-Hole effect model was found to overestimate the soil properties when interpolation was carried out and gave mean prediction error of -0.07 which indicated that the model was highly efficient. With the available water holding capacity map of Lalgudi block, total available water, readily available water and irrigation interval of paddy, sugarcane and banana were estimated. The irrigation interval of paddy, sugarcane and banana were found to vary between 1-2, 3-5 and 2-4 days respectively within Lalgudi block. Adoption of spatial algorithms for estimating the crop water requirement would greatly help the irrigation planners and water policy makers to create efficient regional plans for making precision irrigation under semi-arid vertisols.

CE Database subject headings: Available water holding capacity, Field capacity, Wilting point, Soil texture, Geostatistics, Irrigation, Semivariogram, Spatial autocorrelation, Vertisols

\section{Introduction}

Among different sectors, agriculture is the largest user of globally allocated freshwater with over $70 \%$ of water used for irrigation (Fischer et al., 2007). Improving the water use 
52 efficiency would be a critical response to overcome the growing agricultural water scarcity.

In order to improve the irrigation efficiency, main factors that normally control the storage and release of water in the soil should be known. Among these factors, available water holding capacity (AWC) is a key attribute, since it would quantify the amount of water available for plants that any soil could hold under any agro-climatic condition. Soil available water holding capacity is a key soil hydraulic property, since it quantifies the amount of water available for plants that the soil could hold for a longer period. All farmers should invariably know about this important soil parameter in order to optimize the crop production under any soil and agro-climatic condition.

Obtaining a suitable measurement of AWC would therefore be useful for efficient crop management (Williams et al., 2016) decisions relating to the time of sowing, crop type or level of fertiliser and other inputs. A number of farmers and advisers would be using the AWC data for crop management decisions, which in turn would be associated with the beneficial effects on crop yields (Ngwira et al., 2013; and Lal et al., 2015). Others would use the AWC data more informally in conjunction with the assessments of soil water (soil core, soil water monitoring device) in order to estimate the amount of plant available water. Under irrigation projects, one of the most common ways to define the quantity of irrigation water is associated with the calculation of readily available water or actual water depth (Silva et al., 2011). It would be useful for precision irrigation and proper irrigation scheduling for different crops.

The spatial variation of AWC throughout the irrigated regions should be appropriately considered for efficient scheduling of irrigation. The soil properties, by nature would vary extensively over space and time in any location (Greenholtz et al., 1988). The particular information on spatial variability of a soil parameter could be achieved based on geostatistical analysis. Geostatistics are useful to study the spatial distribution of soil 
properties and also their inconsistency (Liu et al., 2014; Behera et al., 2015). Geostatistics would also help to identify the best interpolation method for acquiring the spatial map of soil parameters (Fromm et al., 1993; Wigginton et al., 2000; Usowicz et al., 2004; Vieira et al., 2007; Zheng et al., 2009; Liu et al., 2014). An accurate estimation of spatial distribution of different soil properties is important for precision agriculture and would be useful for the decision and policy makers to develop suitable plans and strategies.

The spatial maps of AWC parameter prepared from the best interpolation method could be used for efficiently estimating the irrigation water requirement and irrigation interval for different crops at different regions at a given point of time. This information would be very much useful for planners, irrigation engineers and decision makers to recommend and plan efficient water management strategies (De Paz et al., 2015). Greenholtz et al., (1988) examined about the spatial and temporal variability of hydrologic soil characteristics on Glendale clay loam soil. The authors used geostatistical techniques for characterizing the variability of wetness, tension, hydraulic conductivity and texture of a soil. They inferred that the variance of volumetric water content increased based on both depth and time. Geostatistical tools have been used to assess the spatial variation of soil moisture, texture and yield of two rainfed crops viz., vetch-oat and durum wheat (Munoz-Pardo et al., 1990) in a study conducted at College of Agricultural Engineering of Medjezelbab, Tunisia. The mean error was found to significantly decrease with an increase in the sample size.

Brooker et al., (1995) discussed about geostatistical analysis on the depth of topsoil and root zone readily available water at a Vineyard near Waikerie in South Australia. Using the measured semi-variograms, the spatial maps of different soil parameters were prepared for a better understanding and assessment of different soil properties in that region. Goovaerts (1998) mentioned that the basic geostatistical tools like correlogram and semivariogram could be introduced to efficiently characterize the spatial variability of each attribute 
separately as well as their spatial interactions. Weller et al., (2002) used different geostatistical techniques for assessing the spatial variability of soil properties. The authors expressed that Kriging technique would be better than any other interpolation technique (Robinson et al., 2006).

Santra et al., (2008) highlighted that estimation of spatial variation of soil properties would be important for precision farming and environmental modelling. The spatial distribution of water content at field capacity (FC) and permanent wilting point (PWP) at different zones of a farm would govern the available water for an efficient plant growth. Based on a study conducted at Indian Agricultural Research Institute, New Delhi, authors observed that Gaussian model was superior with experimental semivariogram of bulk density, silt and clay contents. The Hole-Effect model was found to be the best to fit the experimental semivariogram of organic carbon content in an alluvial soil. Camacho-Tamayo et al., (2008) determined the spatial variability of different chemical properties, including soil organic carbon (SOC), soil reaction $(\mathrm{pH})$, exchangeable acidity, exchangeable aluminum, available $\mathrm{P}$, calcium $(\mathrm{Ca})$, magnesium $(\mathrm{Mg})$, potassium $(\mathrm{K})$ and sodium $(\mathrm{Na})$ for two Oxisols, with the purpose of identifying guidelines for site-specific agricultural practices. A greater influence of the agricultural intervention on the spatial variability was evident in the upper $10 \mathrm{~cm}$ of soil. A significant spatial dependence was found to exist for most of the soil properties. The information generated would form a basis to derive the guidelines for site-specific agriculture.

Jabro et al., (2010) examined spatial variation of selected soil physical and chemical properties and explored their spatial correlation in the Ap horizon of a Lihen sandy loam soil (sandy, mixed, frigid Entic Haplustoll) within a field of grass-alfalfa Conservation Reserve Program (CRP) land, North Dakota. Results indicated that small to moderate spatial variability existed across the field for different soil properties studied. Nayanaka et al., (2010) 
explored about the spatial variability of agronomically important soil properties of a paddy growing tract in Pulasthigama in Polonnaruwa district in Sri Lanka. The authors suggested that spatial dependencies of soil properties could be used to support the spatial sampling for making a detailed soil mapping. They suggested that the management practices such as fertilizer application, irrigation and tillage operations could be fine-tuned within a field scale to maximize the rice crop production, while minimizing the detrimental effects on environment.

Sharma et al., (2014) conducted experiments on groundnut at Rajkot during kharif 1996 to 2006 to assess efficiency of shallow ploughing, deep ploughing every year, deep ploughing alternate years and deep ploughing once every three years. Treatments were assessed for effect on rainwater use efficiency (RWUE), soil moisture (0-15 and 15-30 cm depth), cumulative depth of infiltration, pod and straw yield, and sustainability yield index (SYI). Significantly higher pod yield of $770 \mathrm{~kg} / \mathrm{ha}$ and straw yield of $2134 \mathrm{~kg} / \mathrm{ha}$ were attained under yearly deep ploughing. Regression models gave coefficient of determination of 0.41 to 0.53 using monthly rainfall, and 0.71 to 0.76 using cumulative rainfall for predicting pod and straw yield. SYI ranged from 19.7 to $24.8 \%$ based on monthly rainfall and 25.6 to $30.9 \%$ based on cumulative rainfall for attaining pod yield, and 35.7 to $40.5 \%$ based on monthly rainfall and 38.0 to $44.8 \%$ based on cumulative rainfall for straw yield. Yearly deep tillage was superior to attain maximum pod and straw yield, SYI, RWUE, benefit-cost ratio and maximum depth of infiltration.

Shit et al., (2016) measured different soil properties like $\mathrm{pH}$, electrical conductivity, available phosphorus, potassium and organic carbon. Random samples were taken from Medinippur Sadar block of Paschim Medinipur district, West Bengal state in India. The spatial variability of these properties have been mapped using different geostatistical models. The study suggested that ordinary kriging interpolation would directly reveal about the spatial 
distribution of different soil properties. Li et al., (2017) examined about the temporal Irrigation Water Productivity trend of different cereal crops over the Hexi Corridor in Northwest China by employing descriptive analysis, trend analysis and change-point analysis. The spatial patterns of dry, average and wet years have been analyzed by the spatial interpolation and spatial autocorrelation methods. The results indicated that the area supported by unit of irrigation water use, fertilization and agricultural film had significant impacts during the whole period.

Elaalem (2017) examined Kriging and Inverse distance weight (IDW) methods for predicting the spatial variability of Exchangeable Sodium Percentage, Cation Exchange Capacity and Calcium Carbonate Percentage in Tripoli, Wadi Almjainin and Bin ghashir at Jeffara Plain, Libya. The study suggested about the usefulness of geostatistical methods for studying the spatial prediction for different soil proprieties. Laekemariam et al., (2018) assessed the spatial variability of soil fertility and mapped the application of fertilizer types using geostatistics. The authors employed ordinary kriging method in their study. The authors have identified nutrient deficient areas and developed site-specific nutrient management based on the study.

Sanches et al., (2019) investigated about the relationship between physical and chemical properties of soil and sugarcane yield, and identified the soil parameters that would efficiently determine the final productivity of a given field. The authors inferred that large volumes of both spatial and temporal data, together with the data mining techniques, allowed the extraction of knowledge and creation of specific management zones in the field in order to support the decision-making process for producers in an efficient manner. Sanches et al., (2019) pointed out that adoption of precision agriculture technologies would be a promising approach to increase the agricultural yields of crops and reducing the production costs. It would comprise of several techniques and technologies for managing the spatial and temporal 
177 variability of crops, and these approaches would improve the yield, profitability and 178 environmental management of fields. These benefits could be essentially obtained through 179 site-specific management that would consider the spatial and temporal variability of a given 180 field.

181 In this paper, we have (i) assessed the spatial variability of soil available water holding capacity using geostatistical approach; and (ii) spatial variation in the irrigation water 183 requirement and irrigation scheduling for major crops grown in Lalgudi block, Tiruchirapalli 184 district, Tamil Nadu in India.

\section{Materials and Methods}

186 Details of the study area

187 The research study was conducted during 2017-19 in Lalgudi block of Tiruchirapalli district, 188 Tamil Nadu, India (Fig. 1). Lalgudi block is situated at 10'52'27" North latitude and $18978^{\circ} 48^{\prime} 57^{\prime \prime}$ East longitude and located at $70 \mathrm{~m}$ above the mean sea level. The northern part of 190 Lalgudi block has a dense dry vegetation and barren lands, while southern part is bounded by 191 Coleroon river. Around 45 villages and two town panchayats exist in this block. Panguni 192 river and Pullambadi canal flow through the block. The total geographical area of the block is 20558 hectares. The soils in Lalgudi block are vertisols with semi-arid climate with long-term average annual rainfall of $877 \mathrm{~mm}$ (mean of 22 years). 


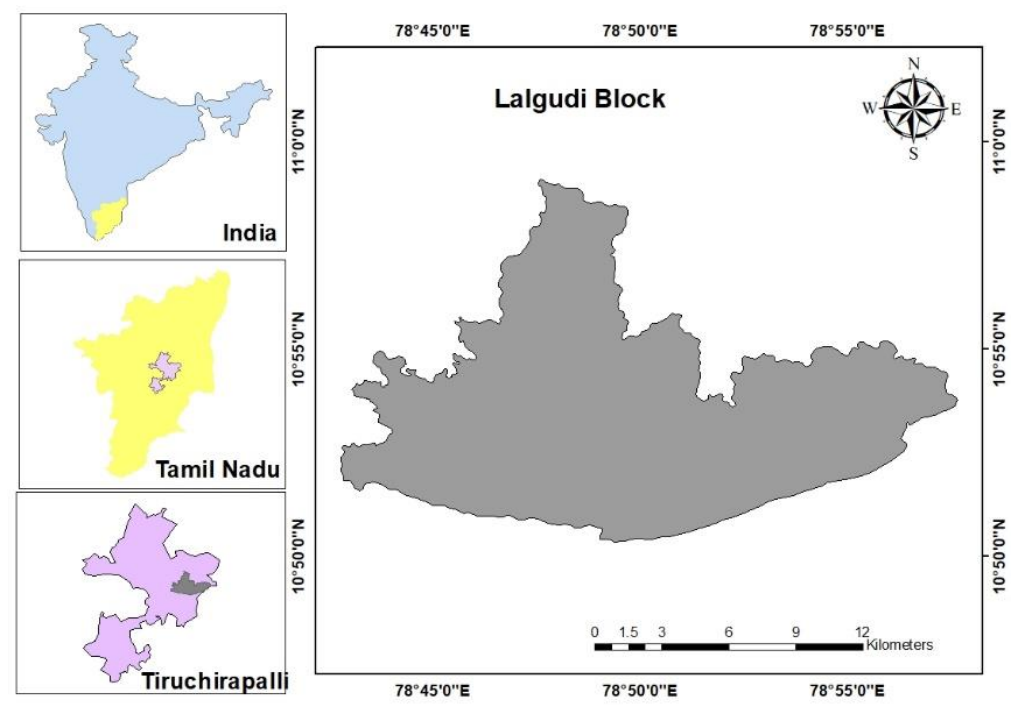

Fig.1. Location of the study area - Lalgudi block

197 Soil analysis

198 Initial soil samples were collected from different parts of Lalgudi block at a soil depth of 30 $\mathrm{cm}$. Twenty samples were collected in the study area at random locations which include the fields of paddy, banana, sugarcane and forest area. Geo-positioning of the sampling locations was recorded with a handheld Global Positioning System (GPS). The location of sampling sites is depicted in Fig. 2. The soil texture was identified using the International Pipette Method or Robinson Pipette Method. The parameters of field capacity and wilting point were determined using the Pressure Plate Apparatus. The difference between field capacity and wilting point would indicate about the available water holding capacity. The experiment was conducted for two years during 2017-18 and 2018-19. 


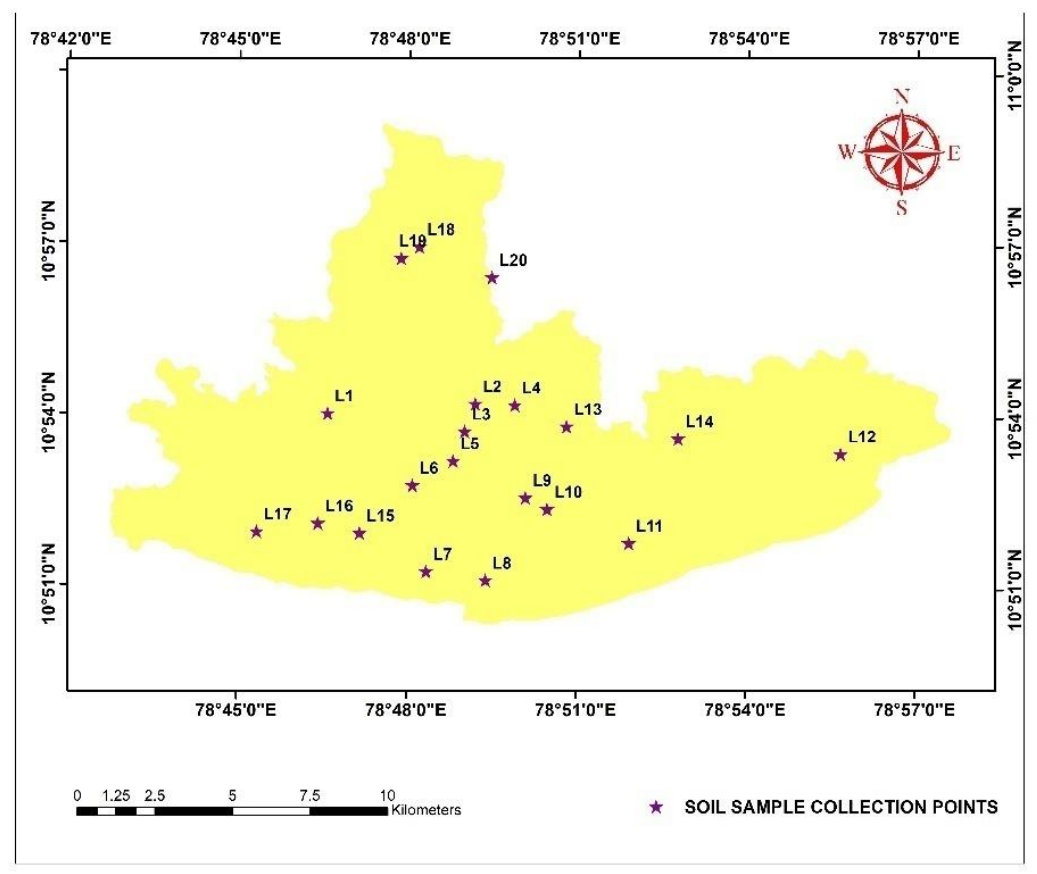

Fig. 2. Location of the study area and sampling sites in Lalgudi block

209

210

211

212

\section{Geostatistical analysis}

\section{Exploratory Spatial Data Analysis of soil parameters}

The exploration of data was done by (i) examining the distribution of dataset; (ii) identifying the trends in the dataset; (iii) assessing the spatial autocorrelation and directional influence of the dataset. In order to carry out the exploration, a new point shape file was created in ArcGIS which included all the soil sample collection points and their corresponding values of field capacity, wilting point and available water holding capacity as records in the attribute table.

The 'Histogram' tool was used to display the frequency distribution of the dataset and summary statistics. The 'Normal QQPlot' tool was used to get the Quantile-Quantile (QQ) plots. It is a graph on which the quantiles from two distributions could be plotted relative to each other. The 'Trend Analysis' tool would help to identify the trends in the input data set and provide 3-dimensional perspective of the data. A unique feature of the 'Trend Analysis' tool is that the values could be projected onto $x, z$ plane and $y, z$ plane as scatter plots. 
223 Polynomials could be fitted to the scatter plots on the projected planes. If the curve through

224 the projected points is a flat one, then no trend would exist. Semivariogram modeling would

225 be a key step between the spatial description and spatial prediction. The empirical

226 semivariogram would provide desired information on the spatial autocorrelation of datasets.

\section{$227 \quad$ Kriging methods}

228 Kriging is the most common interpolation technique adopted by many research workers. It is an advanced geostatistical procedure that provides an estimated surface from scattered set of points with z-values. Ordinary kriging could be considered as an exact interpolator in the sense that the interpolated values or their local average would coincide with those values at the sampled locations (Burrough and McDonnell, 2004). The disjunctive kriging method provides a nonlinear unbiased estimator with the desirable property of minimum variance of errors (Yates et al., 1986). It is better than different linear estimators with respect to the exactness of estimation. In this study, ordinary kriging and disjunctive kriging have been considered for carrying out the interpolation of dataset.

\section{Ordinary Kriging}

238 The ordinary kriging has been widely used in the interpolation due to its simplicity as well as 239 its availability in many Geographical Information Systems (GIS) (Wackernagel, 1995). It provides a smoothed surface and an inexact interpolation. When the dataset follows normal distribution, ordinary kriging could be used. The standard model for using ordinary kriging is

242 given as

243

$$
Z(s)=\mu(s)+\varepsilon(s)
$$

where $\mathrm{Z}(\mathrm{s})$ is the variable of interest, decomposed into a deterministic trend $\mu(\mathrm{s})$ and a random, autocorrelated errors form $\varepsilon(\mathrm{s})$.

\section{Disjunctive Kriging}


Disjunctive kriging is a non-linear type in which the original dataset would be transformed using a series of addictive functions (Yates et al., 1986). Therefore, the standard model could be altered and can be given as

$$
F(Z(s))=\mu(s)+\varepsilon(s)
$$

Where $\mathrm{F}()$ is an arbitrary function of $\mathrm{Z}(\mathrm{s})$. In general, the disjunctive kriging would try to do more than the ordinary kriging for any data set.

\section{Experimental Semivariogram}

Let $\mathrm{Z}$ be an intrinsic random variable function and let $\mathrm{Z}(\mathrm{X})$, for $\mathrm{i}=1,2 \ldots \mathrm{N}$, be a sample of size $\mathrm{N}$. The semivariogram of the random function could be given as

$$
\hat{\gamma}(h)=\frac{1}{2 n(h)} \sum_{i=1}^{n(h)}\left[Z\left(x_{i}+h\right)-Z\left(x_{i}\right)\right]^{2}
$$

$$
\text { the experimental semivariogram. }
$$

\section{Characteristics of Semivariogram}

A semivariogram is a graphical representation of the semivariance and lag distance. The distance at which the semivariogram first flattens out is known as the 'range'. It is the distance after which the variogram levels off. The sample locations that are separated by distances smaller than the range are spatially autocorrelated, whereas the locations farther apart than the range are not spatially autocorrelated. The value of a semivariogram at the range on the y-axis is called 'sill'. The 'nugget' is the value at which the semivariogram intercepts the y-value. In practical terms, the nugget represents the small-scale variability of the data. A portion of that short range variability would be the result of measurement error. The partial sill is the 'sill' minus the 'nugget'. Theoretically, at zero separation distance (lag $=0$ ), the semivariogram value would be ' 0 '. However, at an infinitesimally small separation 
270

271

272

273

274

$275 \quad D=\frac{N}{C}$

276

277

278

279

280

281

282

283

284

285

$286 \gamma(h)=\left\{\begin{array}{l}\frac{2 c}{\pi}\left(\sin ^{-1}(h)+h \sqrt{1-h^{2}}\right), h \leq 1 \\ 1, h>1\end{array}\right.$ correlation based on a given dataset.

\section{Semivariogram models}

\section{Circular model}

when DI is less than 0.25 , then there is a strong correlation; when DI lies between 0.25 and 0.75 , there is a moderate correlation; and when DI is greater than 0.75 , there is a weak

A semivariogram would depict about the spatial autocorrelation of the measured sample points. Once each pair of locations has been plotted, a model could be fit through them. A geostatistical analyst would provide several semivariogram functions to model the empirical semivariogram among which the following six models were used in this study.

The circular semivariogram was estimated by the following model:

287

\section{Spherical model}

288 A spherical semivariogram is a line in shape near the origin. It could be estimated by the 289 following model: 
$290 \quad \gamma(h)=\left\{\begin{array}{l}c\left(\frac{3}{2} \frac{h}{a}-\frac{1}{2}\left(\frac{h}{a}\right)^{3}\right), 0 \leq h<a \\ c, a \leq h\end{array}\right.$ The model is said to be transitive because it would reach a finite sill at a fine range.

292 The spherical model is given as a default model in some packages.

293

294

$295 \quad \gamma(h)=c\left(1-e^{\frac{-3 h}{a}}\right)$

\section{Exponential model}

The exponential semivariogram could be estimated based on the following model:

296

Here, the sill could be approached asymptotically. The exponential model would be

297 useful when there is a larger nugget and a slow rise to the sill.

298

\section{Gaussian model}

299

The Gaussian semivariogram could be estimated based on the following model:

300

$\gamma(h)=c\left(1-e^{-3\left(\frac{h}{a}\right)^{2}}\right)$

The model would approach the sill asymptotically. A graph model has a parabolic 302 form near the origin. It would provide an S-shaped curve.

\section{Pentaspherical model}

304 The pentaspherical semivariogram could be estimated based on the following model:

$305 \gamma(h)=\left\{\begin{array}{l}c\left(\frac{15}{8} \frac{h}{a}-\frac{5}{4}\left(\frac{h}{a}\right)^{3}+\frac{3}{8}\left(\frac{h}{a}\right)^{5}\right), 0 \leq h<a \\ c, a \leq h\end{array}\right.$

\section{Sine Hole Effect model}

307 The Sine Hole effect semivariogram could be estimated based on the following model: 
$308 \gamma(h)=c\left(1-\frac{\sin \left(\pi \frac{h}{a}\right)}{\pi \frac{h}{a}}\right)$

309 The model is not monotonic. It would reach a global maximum and then it would continue a 310 damped oscillation around the sill.

311 Each model could be designed to fit different types of phenomena in an accurate

312 manner. The following cross validation statistics were used to identify the best model for the 313 data set.

314 Cross validation statistics

315 In order to study the interpolator performance, mean error (ME), root-mean-square error 316 (RMSE), average standard error (ASE), mean squared standard error (MSE) and root-mean317 square standardized error (RMSSE) have been determined as

$318 \quad M E=\frac{1}{n} \sum_{i=1}^{n} \varepsilon_{i}$

$319 \quad R M S E=\sqrt{\frac{1}{n} \sum_{i=1}^{n} \varepsilon_{i}^{2}}$

$320 \quad A S E=\sqrt{\frac{1}{n} \sum_{i=1}^{n} \sigma\left(s_{i}\right)}$

$321 \quad M S E=\sqrt{\frac{1}{n} \sum_{i=1}^{n} \frac{\varepsilon_{i}}{\sigma\left(s_{i}\right)}}$

322

$R M S S E=\sqrt{\frac{1}{n} \sum_{i=1}^{n}\left(\frac{\varepsilon_{i}}{\sigma\left(s_{i}\right)}\right)^{2}}$

Generally, the best prediction model would be the one which has standardized mean 324 closer to zero, the smallest root-mean-square prediction error, the average standard error 
325 closer to the root-mean-square prediction error and the standardized root mean square 326 prediction error closer to one.

\section{Validation of interpolation}

328

A part of sample dataset was removed for the purpose of validation and this data set is known as the 'test dataset'. The remaining data set which is known as the 'training dataset' was used to develop the trend and autocorrelation models which are used for the purpose of prediction.

In Geostatistical Analyst, the test and training datasets could be created using the 'Subset Features' tool. About $50 \%$ of the soil samples were considered as a sub-set points for validation. Using these points and the validation option in the Geostatiscal Wizard, interpolation method could be validated. The Mean Prediction error could be used to quantify the validation process which is given as

Mean Prediction Error $=\frac{\sum_{i=1}^{n} Z^{*}\left(x_{i}\right)-Z\left(x_{i}\right)}{n}$

Where $\mathrm{Z}^{*}\left(\mathrm{x}_{\mathrm{i}}\right)$ are the predicted values and $\mathrm{Z}\left(\mathrm{x}_{\mathrm{i}}\right)$ is the computed value at the location of validation points. If the prediction errors are unbiased, the mean prediction error would be closer to zero.

\section{Spatial estimation of available water for different crops}

Using the best prediction model, the Total Available Water (TAW) and Readily Available Water (RAW) were estimated for paddy, banana and sugarcane crops. The Total Available Water for a crop could be given as

$T A W=\left(\theta_{F C}-\theta_{W P}\right) * Z_{r} * 1000$

Where TAW is the total available soil water $[\mathrm{mm}]$ in the root zone, $\theta_{\mathrm{FC}}$ is the water content at the field capacity $\left[\mathrm{m}^{3} \mathrm{~m}^{-3}\right], \theta_{\mathrm{WP}}$ is the water content at the wilting point $\left[\mathrm{m}^{3} \mathrm{~m}^{-3}\right], \mathrm{Z}_{\mathrm{r}}$ is the rooting depth of a particular crop [m]. 
349

350

351

352

Where RAW is readily available soil water in the root zone $[\mathrm{mm}], \mathrm{p}$ is the average fraction of Total Available Soil Water (TAW) that could be depleted from the root zone before the moisture stress (reduction in ET) occurs [0 - 1]. The rooting depth for paddy could be considered as $30 \mathrm{~cm}$, while it is $45 \mathrm{~cm}$ for sugarcane and $30 \mathrm{~cm}$ for banana. The values of $\mathrm{p}$ for paddy, sugarcane and banana were taken from crop evapotranspiration guidelines (Allen et al., 1998) as $0.20,0.65$ and 0.45 respectively. The computations were done using the 'Raster Calculator' tool in ArcGIS software.

\section{Spatial estimation of the irrigation interval}

The irrigation interval could be estimated as

$I_{I}=\frac{T A W}{\text { Peak } E T_{\text {crop }}+\text { Other Water Losses }}$

The Peak ET could be calculated as the maximum of crop evapotranspiration that was estimated using CROPWAT 8.0 software. It was assumed that the other water losses were 1 $\mathrm{mm}$ day $^{-1}$ for sugarcane and banana, while the percolation loss for paddy was $5 \mathrm{~mm}$ day $^{-1}$ (except end stage) (Surendran et al., 2017).

\section{Results and Discussion}

\section{Analysis of soil samples}

The descriptive statistics of field capacity (\%), permanent wilting point (\%) and available water holding capacity (AWC) based on the analysis of 20 soil samples collected at different locations under different soil textures are described in Table 1. Based on the analysis of data of 20 locations, the field capacity ranged from 10.4 to $40.0 \%$ with mean of $23.8 \%$ (CV of $34.2 \%$ ). The permanent wilting point ranged from 3.1 to $36.0 \%$ with mean of $17.1 \%$ (CV of $48.4 \%$ ), while the soil water holding capacity ranged from 2.5 to $10.8 \%$ with mean of $6.6 \%$ (CV of 34.6\%). The available water holding capacity (\%) was found to vary with the soil 
372 texture. Under coarse textured sandy soils, the AWC was significantly lower due to lower

373 field capacity. Under fine textured clay soils, the AWC was significantly lower because of a

374 higher wilting point. But under medium textured silt and loam soils, higher field capacity and

375 lower wilting point were found to provide a significantly higher water holding capacity in the

376 study area.

377 Table 1. Soil parameters observed in different locations in Lalgudi block

\begin{tabular}{|c|c|c|c|c|}
\hline Locations & Soil texture & $\begin{array}{l}\text { Field capacity } \\
\qquad(\%)\end{array}$ & $\begin{array}{l}\text { Wilting point } \\
(\%)\end{array}$ & $\begin{array}{c}\text { Available water holding } \\
\text { capacity }(\%)\end{array}$ \\
\hline $\mathrm{L} 1$ & Clay & 34.1 & 26.1 & 8.0 \\
\hline $\mathrm{L} 2$ & Sandy Loam & 18.4 & 15.2 & 3.2 \\
\hline L3 & Sandy Clay & 28.1 & 21.8 & 6.3 \\
\hline $\mathrm{L} 4$ & Silty Clay Loam & 29.5 & 20.7 & 8.7 \\
\hline L5 & Clay & 40.0 & 36.0 & 4.0 \\
\hline L6 & Sandy Loam & 14.2 & 10.8 & 3.5 \\
\hline L7 & Sandy Loam & 18.5 & 9.5 & 9.0 \\
\hline L8 & Sandy Loam & 16.9 & 10.8 & 6.0 \\
\hline L9 & Sandy Loam & 18.1 & 12.3 & 5.8 \\
\hline L10 & Silt Loam & 27.5 & 16.7 & 10.8 \\
\hline L11 & $\begin{array}{l}\text { Sandy Clay } \\
\text { Loam }\end{array}$ & 22.2 & 13.5 & 8.6 \\
\hline L12 & $\begin{array}{l}\text { Sandy Clay } \\
\text { Loam }\end{array}$ & 23.4 & 19.6 & 3.8 \\
\hline L13 & Clay & 34.3 & 27.5 & 6.8 \\
\hline L14 & Sandy Clay & 31.7 & 29.1 & 2.5 \\
\hline L15 & $\begin{array}{l}\text { Sandy Clay } \\
\text { Loam }\end{array}$ & 27.4 & 19.8 & 7.6 \\
\hline L16 & Sandy Clay & 31.4 & 21.7 & 9.7 \\
\hline L17 & Sandy Loam & 18.6 & 11.3 & 7.3 \\
\hline L18 & Sandy Loam & 14.8 & 8.8 & 6.1 \\
\hline L19 & Loamy Sand & 10.4 & 3.1 & 7.3 \\
\hline L20 & Sandy Loam & 16.1 & 8.6 & 7.5 \\
\hline Mean & & 23.8 & 17.1 & 6.6 \\
\hline $\mathrm{SD}$ & & 8.1 & 8.3 & 2.3 \\
\hline
\end{tabular}




$378 \quad \frac{\mathrm{CV}(\%)}{\mathrm{SD}: \text { Standard deviation }} \quad \mathrm{CV}:$ Coefficient of variation $(\%)$

\section{Soil texture-wise variability in different parameters}

380 The 20 locations (L1 to L20) were found to have 7 soil textures viz., clay, sandy clay, sandy 381 clay loam, sandy loam, silty loam, silty clay loam and loamy sand textures. Under clay soil texture existing in 3 locations (L1, L5, L13), field capacity ranged from $34.1 \%$ (L1) to $40.0 \%$ (L5) with mean of $36.1 \%$ (CV of 9.3\%); while wilting point ranged from $26.1 \%$ (L1) to $36.0 \%$ (L5) with mean of $29.9 \%$ (CV of $17.9 \%$ ); and available water holding capacity ranged from $4.0 \%$ (L5) to $8.0 \%$ (L1) with mean of $6.3 \%$ (CV of $32.8 \%$ ). Under loamy sand soil texture existing in one location (L19), field capacity was $10.4 \%$, while wilting point was $3.1 \%$ and available water holding capacity was $7.3 \%$.

Under sandy clay soil texture observed in 3 locations (L3, L14, L16), field capacity ranged from $28.1 \%$ (L3) to $31.7 \%$ (L14) with mean of $30.4 \%$ (CV of $6.6 \%$ ); while wilting point ranged from $21.7 \%$ (L16) to $29.1 \%$ (L14) with mean of $24.2 \%$ (CV of $17.5 \%$ ); and available water holding capacity ranged from $2.5 \%$ (L14) to $9.7 \%$ (L16) with mean of $6.2 \%$ (CV of 58.4\%). Under sandy clay loam soil texture existing in 3 locations (L11, L12, L15), field capacity ranged from $22.2 \%$ (L11) to $27.4 \%$ (L15) with mean of $24.3 \%$ (CV of $11.2 \%$ ); while wilting point ranged from $13.5 \%$ (L11) to $19.8 \%$ (L15) with mean of $17.6 \%$ (CV of 20.3\%); and available water holding capacity ranged from 3.8\% (L12) to 8.6\% (L11) with mean of $6.7 \%(\mathrm{CV}$ of $38.0 \%)$. of $19.7 \%$ ); and available water holding capacity ranged from $3.2 \%$ (L2) to $9.0 \%$ (L7) with mean of $6.1 \%$ (CV of 32.5\%).Under silt loam soil texture observed in one location (L10), 
402 field capacity was $27.5 \%$, while wilting point was $16.7 \%$ and available water holding 403 capacity was $10.8 \%$. Under silty clay loam soil texture existing in one location (L4), field 404 capacity was $29.5 \%$, while wilting point was $20.7 \%$ and available water holding capacity was $4058.7 \%$. The mean values of field capacity, wilting point and available water holding capacity 406 under different soil textures are described in Fig 3. The analysis indicated that soils under 407 loamy sand soil texture had lowest field capacity of $10.4 \%$ and wilting point of $3.1 \%$, while 408 the soils under clay soil texture had highest field capacity of $36.1 \%$ and wilting point of $40929.9 \%$ under different locations in Lalgudi block. In case of soil water holding capacity, the 410 soils under sandy loam soil texture had lowest capacity of $6.1 \%$, while soils under silt loam 411 texture had highest capacity of $10.8 \%$. 

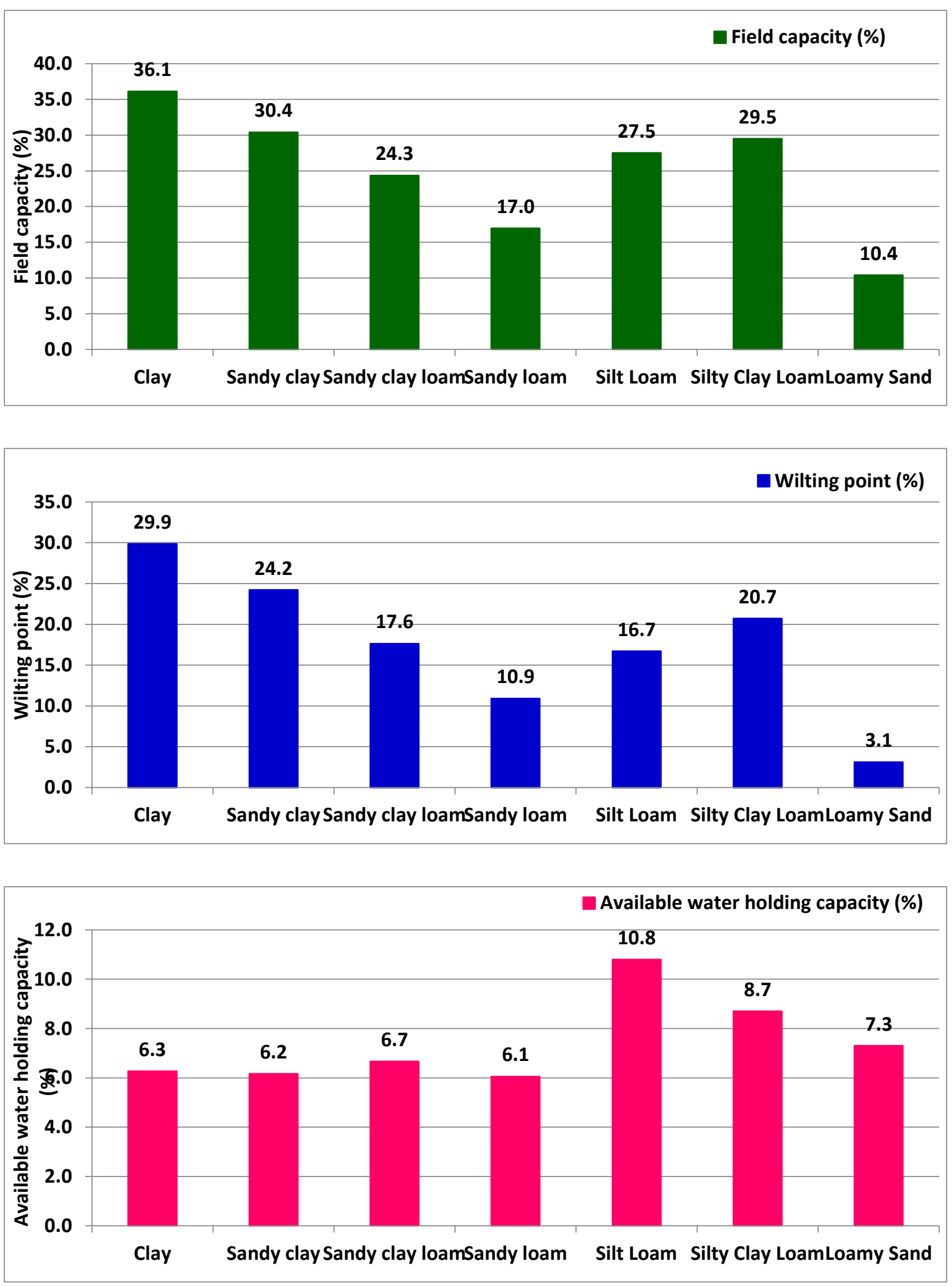

414 Fig. 3. Field capacity, permanent wilting point and available water holding capacity under different soil textures in Lalgudi block 
417 A grouping of different locations into 3 groups was made based on mean and standard 418 deviation of field capacity, wilting point and available water holding capacity and is described in Table 2. The 3 groups have values falling under (i) < (Mean - SD); (ii) (Mean $\mathrm{SD})$ to $($ Mean $+\mathrm{SD})$; and (iii) > (Mean + SD). In case of field capacity, 3 locations of L19,

L6 and L18 have fallen in the group of less than (Mean - SD), while 3 locations of L1, L13 and L5 have fallen in the group of more than (Mean + SD). Fourteen locations viz., L20, L8, L9, L2, L7, L17, L11, L12, L15, L10, L3, L4, L16 and L14 have fallen in the group of (Mean $-\mathrm{SD})$ to $($ Mean $+\mathrm{SD})$.

In case of wilting point, 3 locations of L19, L20 and L18 have fallen in the group of less than (Mean - SD), while 4 locations of L1, L13, L14 and L5 have fallen in the group of more than (Mean + SD). Thirteen locations viz., L7, L6, L8, L17, L9, L11, L2, L10, L12, L15, L4, L16 and L3 have fallen in the group of (Mean - SD) to (Mean + SD). In case of available water holding capacity, 5 locations of L14, L2, L6, L12 and L5 have fallen in the group of less than (Mean - SD), while 3 locations of L7, L16 and L10 have fallen in the group of more than (Mean + SD). Twelve locations viz., L9, L8, L18, L3, L13, L19, L17, L20, L15, L1, L11 and L4 have fallen in the group of (Mean - SD) to (Mean + SD).

Table 2. Grouping of locations based on mean and standard deviation of parameters

\begin{tabular}{|c|c|c|c|c|c|}
\hline Parameter & Mean & SD & $<($ Mean - SD $)$ & $($ Mean - SD) to $($ Mean + SD) & $\begin{array}{l}>(\text { Mean + } \\
\text { SD) }\end{array}$ \\
\hline $\begin{array}{l}\text { Field } \\
\text { capacity (\%) }\end{array}$ & 23.8 & 8.1 & L19 $<$ L6 $<$ L18 & $\begin{array}{l}\mathrm{L} 20<\mathrm{L} 8<\mathrm{L} 9<\mathrm{L} 2<\mathrm{L} 7< \\
\mathrm{L} 17<\mathrm{L} 11<\mathrm{L} 12<\mathrm{L} 15<\mathrm{L} 10 \\
<\mathrm{L} 3<\mathrm{L} 4<\mathrm{L} 16<\mathrm{L} 14\end{array}$ & $\mathrm{~L} 1<\mathrm{L} 13<\mathrm{L} 5$ \\
\hline $\begin{array}{l}\text { Wilting point } \\
(\%)\end{array}$ & 17.1 & 8.3 & $\mathrm{~L} 19<\mathrm{L} 20<\mathrm{L} 18$ & $\begin{array}{l}\mathrm{L} 7<\mathrm{L} 6<\mathrm{L} 8<\mathrm{L} 17<\mathrm{L} 9< \\
\mathrm{L} 11<\mathrm{L} 2<\mathrm{L} 10<\mathrm{L} 12<\mathrm{L} 15 \\
<\mathrm{L} 4<\mathrm{L} 16<\mathrm{L} 3\end{array}$ & $\begin{array}{l}\mathrm{L} 1<\mathrm{L} 13< \\
\mathrm{L} 14<\mathrm{L} 5\end{array}$ \\
\hline $\begin{array}{l}\text { Available } \\
\text { water } \\
\text { holding } \\
\text { capacity }(\%)\end{array}$ & 6.6 & 2.3 & $\begin{array}{l}\mathrm{L} 14<\mathrm{L} 2<\mathrm{L} 6< \\
\mathrm{L} 12<\mathrm{L} 5\end{array}$ & $\begin{array}{l}\mathrm{L} 9<\mathrm{L} 8<\mathrm{L} 18<\mathrm{L} 3<\mathrm{L} 13< \\
\mathrm{L} 19<\mathrm{L} 17<\mathrm{L} 20<\mathrm{L} 15<\mathrm{L} 1 \\
<\mathrm{L} 11<\mathrm{L} 4\end{array}$ & $\begin{array}{l}\text { L7 }<\text { L16 < } \\
\text { L10 }\end{array}$ \\
\hline
\end{tabular}




\section{Relationship between different soil parameters}

436 The estimates of correlation between different soil parameters and their effects on each other 437 are described in Fig 4. Field capacity was found to have a positive effect on the wilting point 438 indicating an increase in the wilting point for an increase in the field capacity. Wilting point 439 changed by a significant coefficient of $0.980 \%$ for an unit change in the field capacity with 440 significant predictability $\left(\mathrm{R}^{2}\right)$ value of 0.923 . Field capacity had a positive effect on the 441 available water holding capacity indicating an increase in the available water holding 442 capacity for an increase in the field capacity. However, available water holding capacity 443 changed by a non-significant coefficient of $0.017 \%$ for an unit change in the field capacity 444 with non-significant predictability $\left(\mathrm{R}^{2}\right)$ value of 0.003 . Wilting point had a negative effect on 445 the available water holding capacity indicating a decrease in the available water holding 446 capacity for an increase in the wilting point. Available water holding capacity changed by a 447 non-significant coefficient of $-0.060 \%$ for an unit change in the wilting point with non448 significant predictability $\left(\mathrm{R}^{2}\right)$ value of 0.047 

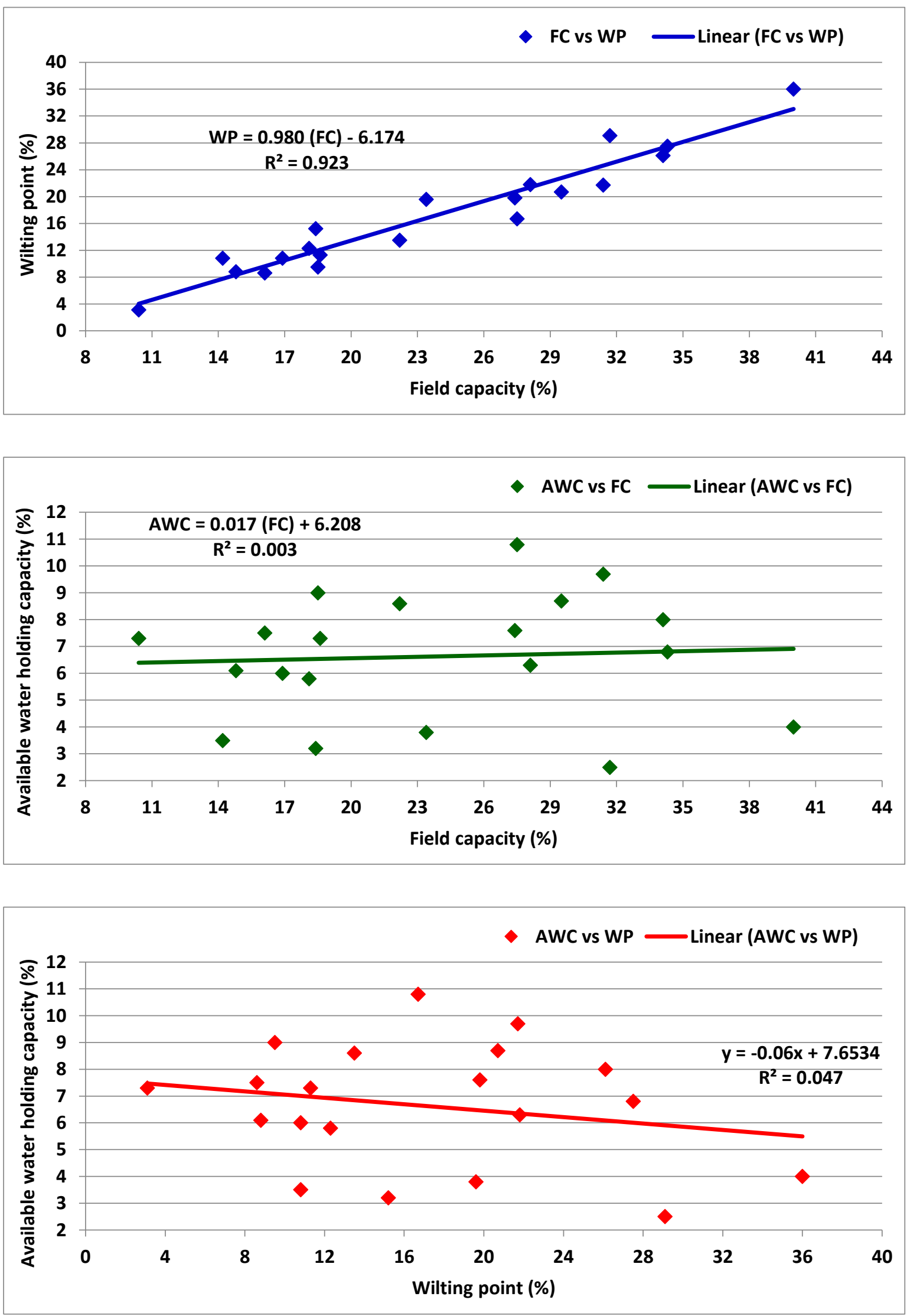
Fig. 4. Relationship between different parameters in Lalgudi block: (a) FC vs WP (Top); (b)

\section{Geostatistic analysis}

\section{Assessment of soil parameters}

454 The descriptive statistics viz., minimum, maximum, mean, median, standard deviation and coefficient of variation (\%) of soil parameters are given in Table 1 and are depicted in Fig. 5.

The available water holding capacity in the soil based on the soil samples collected in 20

457 applied for the dataset without carrying out a suitable data transformation.

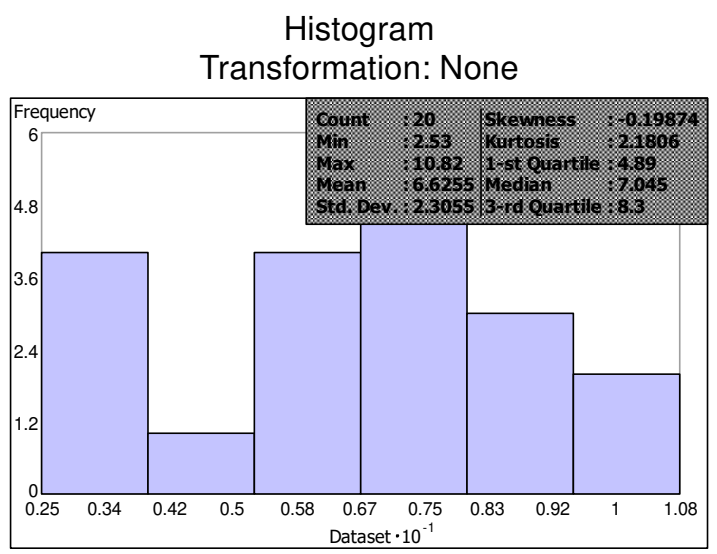

Dataset : Soil_Allpts Attribute: AWHC

a) Without data transformation

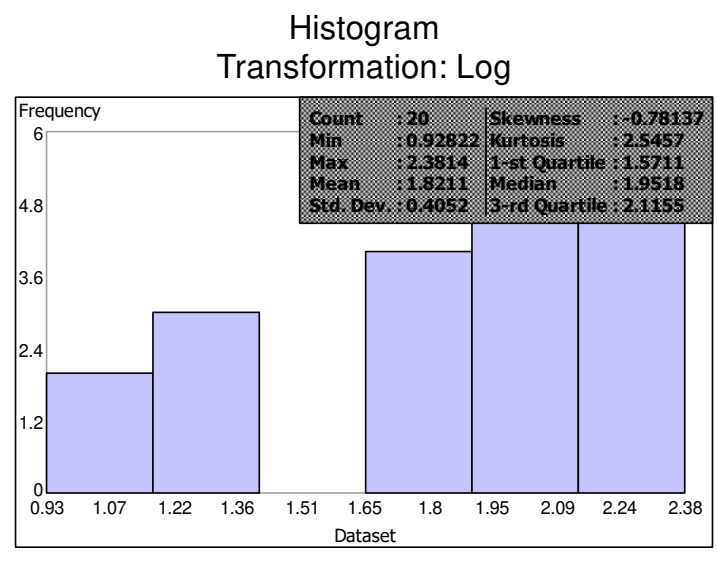

Dataset : Soil_Allpts Attribute:AWHC

b) With log transformation

Fig. 5. Assessment of soil available water-holding capacity in Lalgudi block depicted in Fig. 5b. The mean and median of the log transformed dataset were found to be closer to each other. The transformed data was found to have a mean AWC of 1.821 and median AWC of 1.951. This indicated normal distribution of the log transformed dataset of 
available water holding capacity. De Paz et al., (2015) observed about non-normal

468

469

470

471

472

473

474

475

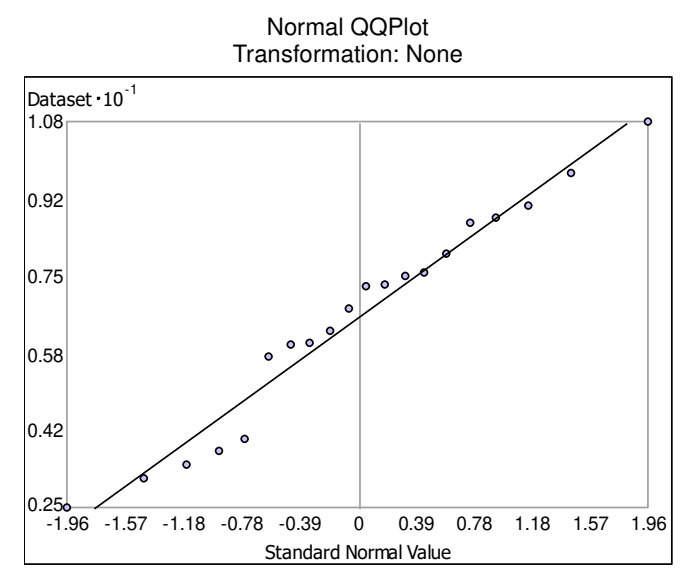

Dataset : Soil_Allpts Attribute: AWHC

a) Without data transformation

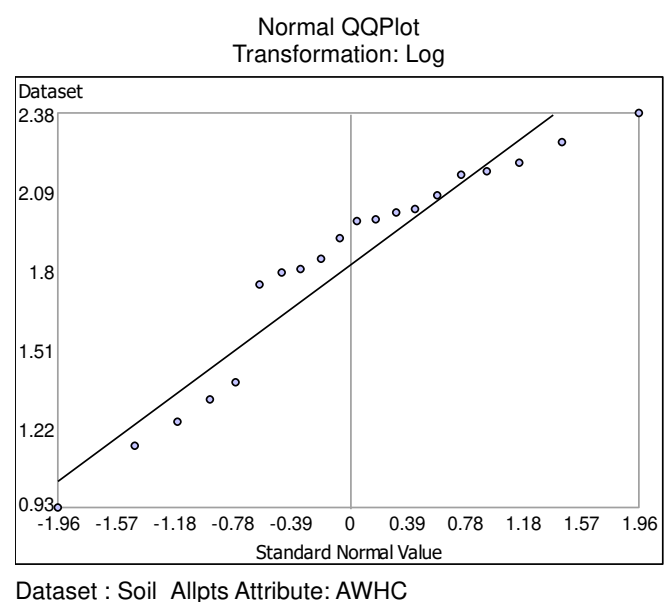

b) With log transformation

476 Fig. 6. Normal QQ plots of soil available water-holding capacity in Lalgudi block

478 line in case of the log-transformed dataset. This indicated about the closeness of the dataset to 479 be normally distributed when the data transformation was done compared to the nontransformed data. 
482

483

484

485

486

487

488

489

490

491

492

493

494

495

496

Trend analysis was carried out for the data of soil parameters. The trend exhibited by the soil available water holding capacity is depicted in Fig. 7 which would help in identifying the presence of trend in the dataset.

Trend Analysis

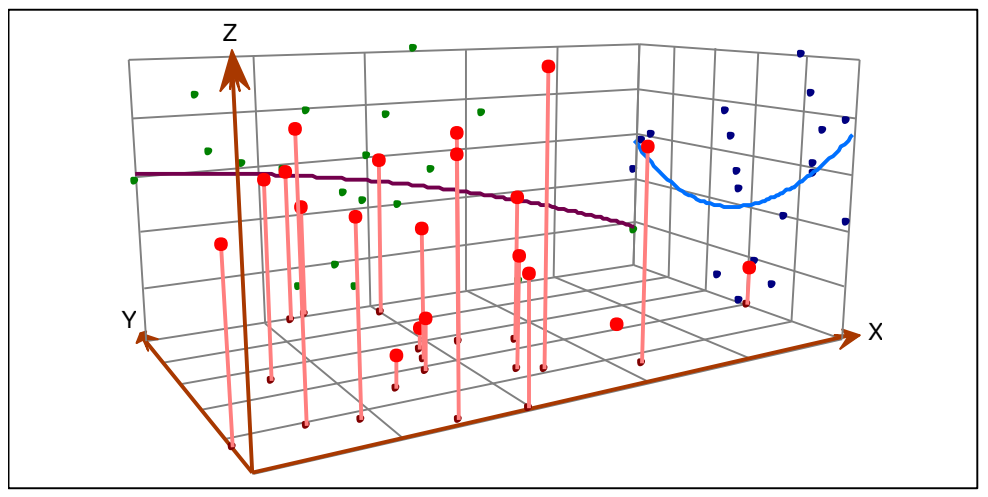

Dataset : Soil_Allpts Attribute: AWHC

Fig. 7. Trend analysis of soil available water holding capacity

The polynomial curve (blue line on the xz-plane) indicated about the existence of a trend. The available water holding capacity was found to have an upside down u-shape curve which indicated that it had a significantly higher influence from the boundaries towards its center. The curve through the projected points in the yz-plane was found to be flat in all the three datasets which indicated that there was no trend in the yz-plane for the sample dataset considered in the study.

\section{Semivariogram cloud of soil properties}

The semivariogram cloud would provide about the information on spatial autocorrelation of the dataset, apart from giving scope for identifying outliers in the dataset. The semivariogram cloud for available water holding capacity is depicted in Fig 8. 


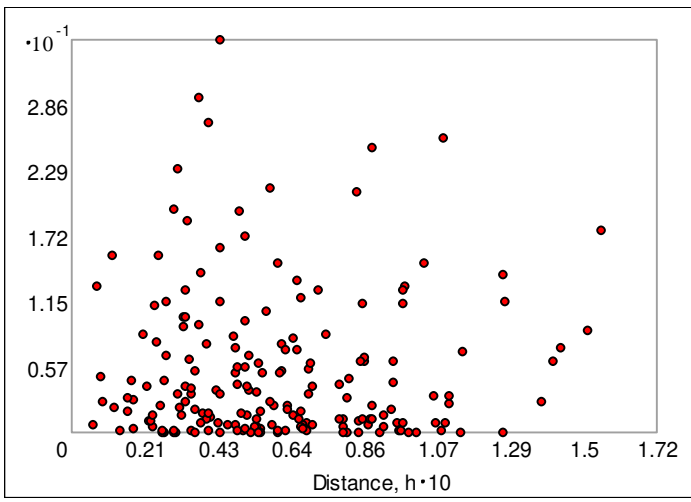

498 Fig. 8. Semivariogram cloud for soil AWC in Lalgudi block

Each red dot would indicate about the empirical semivariogram value of the two soil

500 samples plotted against the distance of separation. Based on Fig.8, most of the points were

501 found to be close to one another. This indicated that the points are alike with each other.

502 When closely examined, it is observed that as the distance increases, the pair of points of

503 available water holding capacity were found to be far apart.

\section{Characteristics of semivariograms}

505 The experimental semivariogram fitted with six models viz., Circular, Spherical, Exponential, 506 Gaussian, Pentaspherical and Sine-Hole effect and two kriging methods viz., ordinary and 507 disjunctive methods for the available water holding capacity are depicted in Fig. 9 based on 508 ordinary kriging and Fig 10 based on disjunctive kriging method.

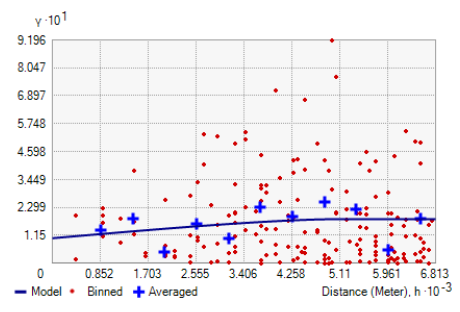

(a) Circular

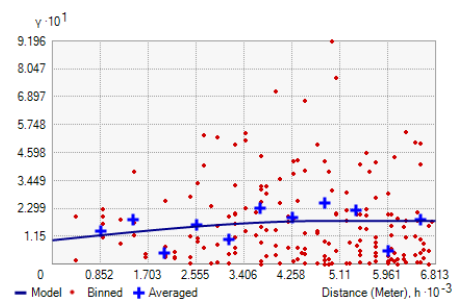

(b) Spherical

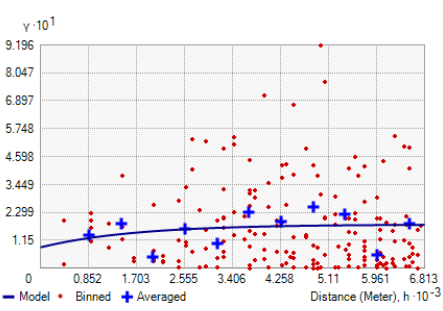

(c) Exponential 


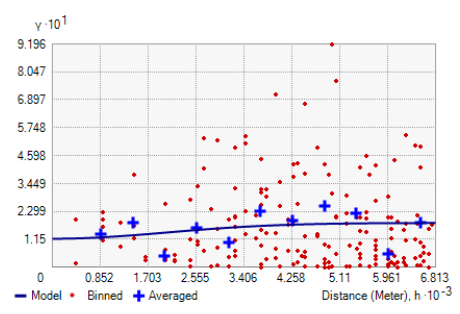

(d) Gaussian

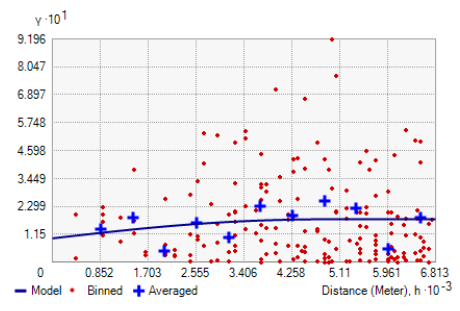

(e) Pentaspherical

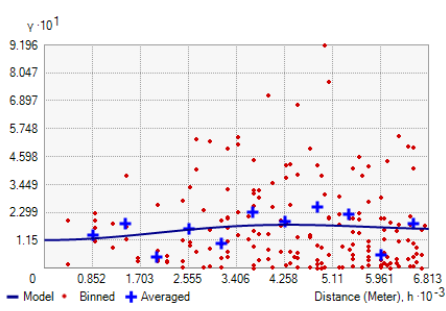

(f) Sine-Hole Effect
509

510

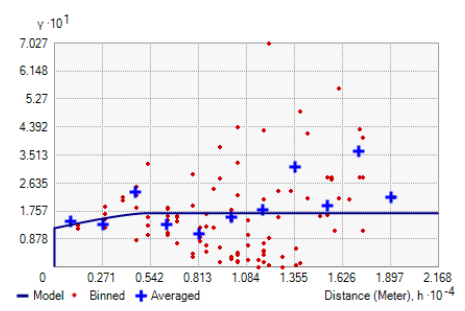

(a) Circular

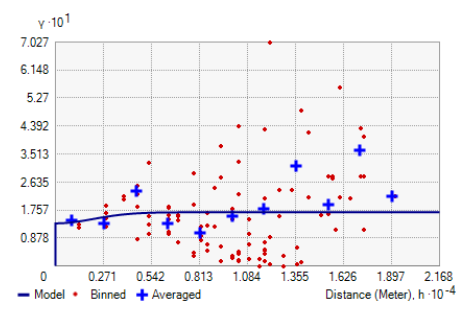

(d) Gaussian

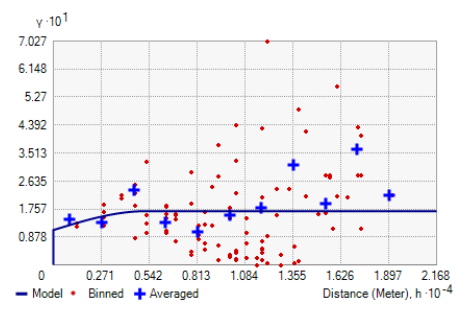

(b) Spherical

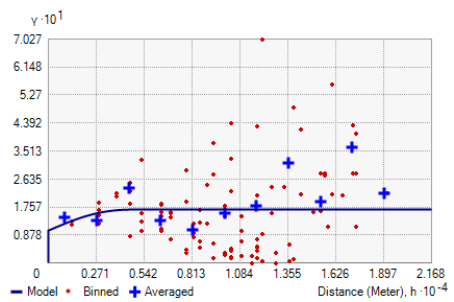

(e) Pentaspherical

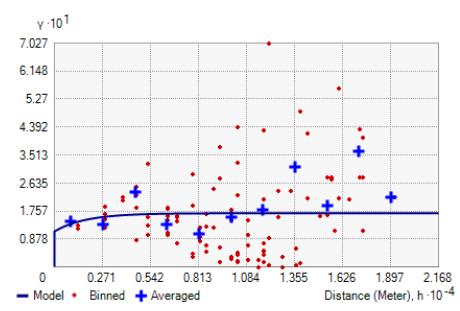

(c) Exponential

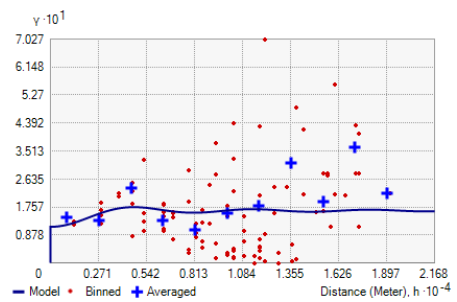

(f) Sine-Hole Effect

511 Fig. 10. Semivariograms for available water holding capacity in Lalgudi block using

512 Disjunctive Kriging

Based on the semivariograms, the characteristics of a semivariogram like nugget, sill

514 and range were estimated for the available water holding capacity and are given in Table 3 based on ordinary kriging and Table 4 based on disjunctive kriging. The dependency index of each model was estimated and nature of the spatial dependency of each dataset is indicated in

517 the respective Tables. Under the Ordinary Kriging method, a range of $4957 \mathrm{~m}$ was observed. The nugget ranged from 0.0854 for Exponential model to 0.1168 for Gaussian model with 
519

520

521

522

523

524

525

526

527

\begin{tabular}{lcccccc}
\hline Model & Nugget & $\begin{array}{c}\text { Partial } \\
\text { Sill }\end{array}$ & $\begin{array}{c}\text { Range } \\
(\mathrm{m})\end{array}$ & Sill & DI & $\begin{array}{c}\text { Spatial } \\
\text { Dependency }\end{array}$ \\
\hline Spherical & 0.0980 & 0.0801 & 4957 & 0.1781 & 0.55 & Moderate \\
Circular & 0.1025 & 0.0783 & 4957 & 0.1808 & 0.57 & Moderate \\
Exponential & 0.0854 & 0.0944 & 4957 & 0.1798 & 0.47 & Moderate \\
Gaussian & 0.1168 & 0.0650 & 4957 & 0.1818 & 0.64 & Moderate \\
Pentaspherical & 0.0979 & 0.0792 & 4957 & 0.1771 & 0.55 & Moderate \\
Sine-Hole Effect & 0.1153 & 0.0519 & 4957 & 0.1672 & 0.69 & Moderate \\
\hline Mean & 0.1027 & 0.0748 & & 0.1775 & 0.58 & \\
\hline
\end{tabular}

mean of 0.1027 . The sill ranged from 0.1672 based on Sine-Hole effect model to 0.1818 based on Gaussian model with mean of 0.1775 , while the partial sill ranged from 0.0519 based on Sine-Hole effect model to 0.0944 based on Exponential model with mean of 0.0748 . Based on the analysis, the dependency index ranged from 0.47 under the Exponential model to 0.69 under the Sine-Hole effect model with mean of 0.58 . The spatial dependency was 'moderate' based on all the 6 models calibrated for the data of available water holding capacity under vertisols located in Lalgudi block.

Table 3. Characters of available water holding capacity semivariograms with Ordinary Kriging

528 was found to range from 0.1016 for Pentaspherical model to 0.1337 for Gaussian model with mean of 0.1153 . Compared to this, the sill ranged from 0.1642 based on the Sine-Hole effect model to 0.1688 based on the Spherical model with mean of 0.1677 , while the partial sill ranged from 0.0347 based on the Gaussian model to 0.0661 based on the Pentaspherical model with mean of 0.0525 . The Pentaspherical model gave minimum dependency index of 0.61, while the Gaussian model gave maximum dependency index of 0.79 compared to the mean value of 0.69 . The spatial dependency was found to be 'weak' under Gaussian model, 


\begin{tabular}{lcccccc}
\hline Model & Nugget & $\begin{array}{c}\text { Partial } \\
\text { Sill }\end{array}$ & $\begin{array}{c}\text { Range } \\
(\mathrm{m})\end{array}$ & Sill & DI & $\begin{array}{c}\text { Spatial } \\
\text { Dependency }\end{array}$ \\
\hline Spherical & 0.1096 & 0.0592 & 5199 & 0.1688 & 0.65 & Moderate \\
Circular & 0.1217 & 0.0470 & 5199 & 0.1687 & 0.72 & Moderate \\
Exponential & 0.1114 & 0.0572 & 5199 & 0.1686 & 0.66 & Moderate \\
Gaussian & 0.1337 & 0.0347 & 5199 & 0.1684 & 0.79 & Weak \\
Pentaspherical & 0.1016 & 0.0661 & 5199 & 0.1677 & 0.61 & Moderate \\
Sine-Hole Effect & 0.1135 & 0.0507 & 5199 & 0.1642 & 0.69 & Moderate \\
\hline Mean & 0.1153 & 0.0525 & & 0.1677 & 0.69 & \\
\hline
\end{tabular}

while it was 'moderate' under all the remaining 5 models calibrated for the data of available water holding capacity under vertisols located in Lalgudi block.

Table 4. Characters of available water holding capacity semivariograms with Disjunctive Kriging
541 
555

556

557

558

559

560

561

562

563

564

565

566

567

568

\begin{tabular}{lcccccc}
\hline Model & ME & RMSE & MSE & RMSSE & ASE & Remarks \\
\hline Spherical & 0.0123 & 2.5403 & -0.0722 & 0.8222 & 3.1664 & Overestimates \\
Circular & 0.0088 & 2.5118 & -0.0691 & 0.8157 & 3.1456 & Overestimates \\
Exponential & 0.0127 & 2.5718 & -0.0734 & 0.8215 & 3.1939 & Overestimates \\
Gaussian & 0.0200 & 2.5186 & -0.0658 & 0.8139 & 3.1604 & Overestimates \\
Pentaspherical & -0.0877 & 2.4919 & -0.0921 & 0.8417 & 3.0476 & Overestimates \\
Sine-HoleEffect & -0.1070 & 2.3993 & -0.0876 & 0.8148 & 3.0214 & Overestimates \\
\hline Mean & -0.0235 & 2.5056 & -0.0767 & 0.8216 & 3.1200 & \\
\hline
\end{tabular}

\section{Cross validation statistics of semivariograms}

The cross validation statistics determined were found to be useful for predicting the best performing model for interpolation of water holding capacity data in the study area. In order to study the interpolator performance, the results of cross validation parameters like mean error (ME), root-mean-square error (RMSE), average standard error (ASE), mean squared standard error (MSE) and root-mean-square standardized error (RMSSE) are given in Table 5 based on Ordinary Kriging method and Table 6 based on Disjunctive Kriging method.

The ME ranged from -0.1070 under Sine-Hole effect model to 0.0200 under Gaussian model with mean of -0.0235 , while the RMSE ranged from 2.3993 under Sine-Hole effect model to 2.5718 under Exponential model with mean of 2.5056. The MSE ranged from 0.0921 under Pentaspherical model to -0.0658 under Gaussian model with mean of -0.0767 , while the RMSSE ranged from 0.8139 under Gaussian model to 0.8417 under Pentaspherical model with mean of 0.8216 over 6 models calibrated under the Ordinary Kriging method.

Table 5. Cross validation statistics of available water holding capacity with Ordinary Kriging
569

570

571

572 
574 0.0292, while the RMSSE ranged from 0.8077 under Sine-Hole effect model to 0.8260 under

575 Pentaspherical model with mean of 0.8152 over 6 models calibrated under the Disjunctive

576 Kriging method.

577 Table 6. Cross validation statistics of available water holding capacity with Disjunctive $578 \quad$ Kriging

\begin{tabular}{lcccccc}
\hline Model & ME & RMSE & MSE & RMSSE & ASE & Remarks \\
\hline Spherical & 0.1087 & 2.2700 & 0.0280 & 0.8210 & 2.8039 & Overestimates \\
Circular & 0.1061 & 2.2658 & 0.0302 & 0.8117 & 2.8156 & Overestimates \\
Exponential & 0.1038 & 2.2980 & 0.0268 & 0.8161 & 2.8341 & Overestimates \\
Gaussian & 0.1059 & 2.2697 & 0.0310 & 0.8089 & 2.8266 & Overestimates \\
Pentaspherical & 0.1050 & 2.2783 & 0.0252 & 0.8260 & 2.8031 & Overestimates \\
Sine-HoleEffect & 0.1098 & 2.1744 & 0.0341 & 0.8077 & 2.7566 & Overestimates \\
\hline Mean & 0.1066 & 2.2594 & 0.0292 & 0.8152 & 2.8100 & \\
\hline
\end{tabular}

579

580

581

582

583

584

585

586

587

588

589

590

591

For any model, if (i) RMSE is less than ASE and (ii) RMSSE is less than 1, then the model would overestimate the given dataset. Based on the results, it is observed that the available water holding capacity was overestimated by all the six models using both methods of kriging. The best prediction method should have minimum RMSE value. Finally, it is observed that this approach gave lower RMSE values for prediction of available water holding capacity. Mardikis et al., (2005) have reported a lower error value when interpolation took place only once in their study.

While comparing the ordinary kriging and disjunctive kriging carried out for the available water holding capacity, it is observed that the models calibrated under disjunctive kriging gave lower RMSE values (Table 4 and Table 5). Among the six models calibrated under disjunctive kriging, Sine-Hole effect model gave lower RMSE value indicating the superiority of the model for predicting the available water holding capacity. 
592

593

594

595

596

597

598

599

600

601

602

603

604

605

606

607

608

609

610

611

612

613

614

615

Hence, for any further spatial estimation of the water requirement of crops, the interpolated available water holding capacity map with disjunctive kriging has been used. Santra et al., (2008) observed about the superiority of Sine Hole-effect model. They observed that this model was the best fit for the experimental semivariogram of the soil organic carbon content.

\section{Validation of the best prediction model}

In order to validate the best prediction model, $50 \%$ of the dataset was considered as a subset and mean prediction error was estimated. It was found that the Sine-Hole effect model under Disjunctive Kriging gave a prediction error of -0.07 which is closer to zero compared to other models. Hence, the spatial estimation of available water holding capacity with the Sine-Hole effect model under Disjunctive Kriging would be superior for making interpolation of the available water holding capacity.

The available water holding capacity map for Lalgudi block prepared with the SineHole effect model under Disjunctive Kriging is depicted in Fig. 11. The interpolated values of available water holding capacity were found to range from 4.9 to $8.2 \%$ in the study area. From Fig. 11, it is observed that most of the areas in Lalgudi block had available water holding capacity in the range of 6.1 to $7.0 \%$. Thus the map would be useful for (i) making an efficient spatial estimation of the water requirement for different crops; and (ii) grouping the villages based on the crop water requirement.

\section{Spatial available water and irrigation interval for different crops}

Using the available water holding capacity map prepared by considering the Sine-Hole effect model calibrated under Disjunctive Kriging, the total available water, readily available water and irrigation interval have been estimated for paddy, banana and sugarcane crops and are given in Table 7. The available water content observed in different villages has been grouped 
into three categories and the villages coming under each category have also been described in

617 Table 7.

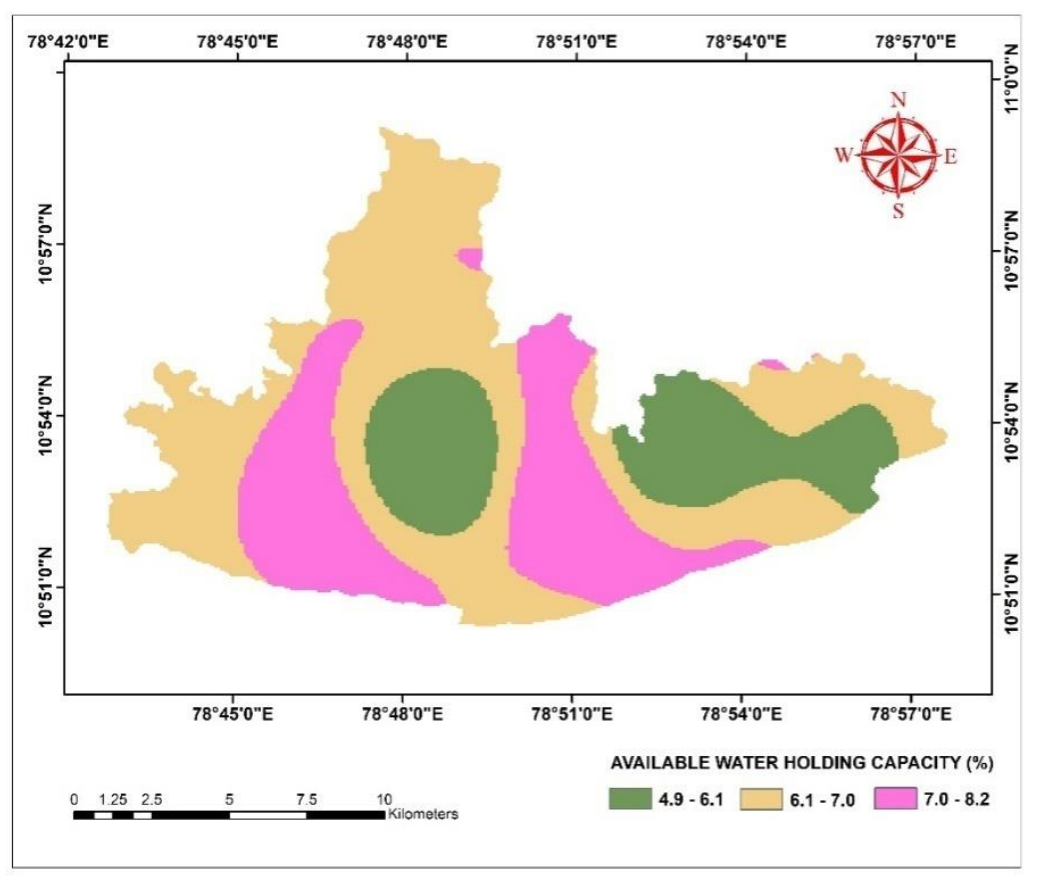

619 Fig. 11. Available water holding capacity in different villages in Lalgudi block

The results obtained based on the geostatistical analysis of the data were similar to the observations made by farmers when interacted with them during the field visit. The paddy growers reported that the standing water depth could be maintained for paddy crop by irrigating the field once in two days at Edayathamangalam, Kuhoor, Kelanbil, and every day at Nagar, Angarai, Thirumangalamand Sembarai villages. The sugarcane farmers expressed that irrigation has to be provided either once in three days or five days for sugarcane crop. Farmers in Marudhur reported that irrigation will be provided to sugarcane at a maximum interval of five days.

In case of sugarcane, if it is first ratoon crop, then the irrigation interval could be prolonged since the depth of roots would be deeper and the total available water would also be more. Similarly, it could be adopted for banana crop since banana growers would go for 
either first or second ratoon in banana. Hence, the spatial interpolation of soil properties was

highly consistent with the actual practice adopted by farmers in the study area.

Table 7. Available water and irrigation interval for different crops in Lalgudi block

\begin{tabular}{|c|c|c|c|c|}
\hline Villages & Crops & $\begin{array}{l}\text { TAW } \\
(\mathrm{mm})\end{array}$ & $\begin{array}{l}\text { RAW } \\
(\mathrm{mm})\end{array}$ & $\begin{array}{l}\text { Irrigation } \\
\text { Interval } \\
\text { (Days) }\end{array}$ \\
\hline \multirow{3}{*}{$\begin{array}{l}\text { Agalanganallur, Nagar, Angarai, } \\
\text { Thirumangalam, Sembarai, } \\
\text { Mettupatti, Thinniyam, } \\
\text { T.Kalvikudi, AlangudiMahajanam }\end{array}$} & Paddy & $14-18$ & $2-3$ & 1 \\
\hline & Sugarcane & $22-27$ & $14-18$ & 3 \\
\hline & Banana & $14-18$ & $6-8$ & 2 \\
\hline \multirow{3}{*}{$\begin{array}{l}\text { Thachakurichi, Magilambadi, } \\
\text { Puthuruthamanur, Neikuppai, } \\
\text { Edayathamangalam, Kuhoor, } \\
\text { Kelanbil, Ariyur, NathamMangudi, } \\
\text { Madakudi, Thalakudi, Appadurai, } \\
\text { Esankorai, Pudukudi }\end{array}$} & Paddy & $18-21$ & $3-4$ & 2 \\
\hline & Sugarcane & $27-31$ & $18-20$ & 4 \\
\hline & Banana & $18-21$ & $8-9$ & 3 \\
\hline \multirow{3}{*}{$\begin{array}{l}\text { R.Valavanur, Marudhur, } \\
\text { Sirumarudhur, Valadi, } \\
\text { Pamparamchutti, Thirumanamedu, } \\
\text { Sevanthinathapuram }\end{array}$} & Paddy & $21-24$ & $4-5$ & 2 \\
\hline & Sugarcane & $31-37$ & $20-24$ & 5 \\
\hline & Banana & $21-24$ & $9-11$ & 4 \\
\hline
\end{tabular}

\section{Conclusion}

The goal of the agricultural producers would be to maintain the field at or near field capacity.

When there is a deficit in the amount of water in the soil, the soil profile would need to be replenished by either precipitation or irrigation. Geostatistics were applied for identifying the best interpolation method to acquire the spatial map of available water holding capacity. The initial data exploration indicated about the non-normal distribution of available water holding capacity and hence log-transformation was done before using kriging method. Ordinary kriging and Disjunctive kriging have been explored with six different models viz., Circular, Spherical, Exponential, Gaussian, Pentaspherical and Sine-Hole effect model. The models have been used for the spatial prediction of available water-holding capacity. A relatively lower Root Mean Square Error was observed for all the six models which was in the range of 
646

647

648

649

650

651

652

653

654

655

656

657

658

659

660

661

662

663

664

665

666

667

668

669

2.1 to 2.5 . The cross validation statistics indicated that the Sine-Hole effect model with

Disjunctive Kriging of available water holding capacity was superior for interpolation with minimum Root Mean Square Error value $($ RMSE $=2.17)$ and with moderate spatial dependency. It was found to overestimate the soil properties when interpolation was carried out. The validation of Sine-Hole effect model gave mean prediction error equal to -0.07 which indicated an efficient performance of the model. Hence, with the available water holding capacity map of Lalgudi block, the total available water, readily available water and irrigation interval of paddy, sugarcane and banana crops were estimated. The irrigation interval of paddy, sugarcane and banana varied between 1-2, 3-5 and 2-4 days respectively within the block. Finally, the block was grouped into three categories based on the available water and the villages falling in those categories have been assessed. The key would be for the farmers to understand the distinctions of the soil water holding capacity, apart from efficiently managing the water so that the crops would not be either irrigated excessively or suffer from drought condition.

\section{Data Availability Statement}

a. Some or all data, models, or code that support the findings of this study are available from the corresponding author upon reasonable request.

b. All data, models, and code generated or used during the study appear in the submitted article.

\section{References}

Behera, S.K., and Shukla, A.K. (2015). "Spatial distribution of surface soil acidity, electrical conductivity, soil organic carbon content and exchangeable potassium, calcium and magnesium in some cropped acid soils of India”. Land Degrad. \& Develop., 26(1), 7179. 
670 Brooker, P.I., Winchester, J.P., and Adams, A.C. (1995). "A Geostatistical Study of Soil Data

671

672

673

674

675

676

677

678

679

680

681

682

683

684

685

686

687

688

689

690

691

692

693

694 from an Irrigated Vineyard near Waikerie, South Australia”. Environ. Internat., 21(5), 699-704.

Burrough P.A., and McDonnell, R.A. (2004). "Principles of Geographical Information Systems”. Oxford University Press, New York.

Camacho-Tamayo, J.H., Luengas, C.A., and Leiva, F.R. (2008). "Effect of agricultural intervention on the spatial variability of some soils chemical properties in the eastern plains of Colombia". Chilean J. Agric. Res., 68(1), 42-55.

De Benedetto, D., Castrignanò, A., and Quarto, R. (2013). “A Geostatistical Approach to Estimate Soil Moisture as a Function of Geophysical Data and Soil Attributes". Procedia Environmental Sciences, 19, 436-445. doi: 10.1016/j.proenv.2013.06.050.

De Paz, J.M., Albert, C., Visconti, F., Jiménez, M.G., Ingelmo, F., and Molina, M.J. (2015). "A new methodology to assess the maximum irrigation rates at catchment scale using geostatistics and GIS”. Precision Agric., 16(5), 505-531. doi: 10.1007/s11119-0159392-y.

Elaalem, M.M. (2017). "Spatial Variability of Some Soil Chemical Proprieties in Jeffara Plain, Libya (Case Study: Tripoli, Wadi Almjainin and Bin Ghashir)". The Libyan J. Agric., 22(1), 19-34.

Fischer, G., Tubiello, F.N., van Velthuizen, H. and Wiberg, D.A. (2007). "Climate change impacts on irrigation water requirements: Effects of mitigation, 1990-2080". Technological Forecasting and Social Change, 74, 1083-1107, https://doi.org/10.1016/j.techfore.2006.05.021.

Fromm H, Winter K, and Filser, J. (1993). “The influence of soil type and cultivation system on the spatial distributions of the soil fauna and microorganisms and their interactions". Geoderma, 60, 109-118. 
695 Goovaerts, P. (1998). "Geostatistical tools for characterizing the spatial variability of

696

697

698

699

700

701

702

703

704

705

706

707

708

709

710

711

712

713

714

715

716

717

718

719 microbiological and physico-chemical soil properties". Biology and Fert. Soils, 27(4), 315-334.

Greenholtz, D.E., Yeh, T.C.J., Nash, M.S.B., and Wierenga, P.J. (1988). “Geostatistical Analysis of Soil Hydrologic Properties in a Field Plot”. J. Contaminant Hydro., 3, 227250.

Jabro, J.D., Stevens, W.B., Evans, R.G., and Iversen, W.M. (2010). "Spatial variability and correlation of selected soil properties in the Ap horizon of a CRP grassland". Applied Eng. in Agric., 26(3), 419.

Laekemariam, F., Kibret, K., Mamo, T., and Shiferaw, H. (2018). “Accounting Spatial Variability of Soil Properties and Mapping Fertilizer Types Using Geostatistics in Southern Ethiopia”. Communi. in Soil Sci. and Plant Anal., 49(1), 124-137. doi: 10.1080/00103624.2017.1421656.

Lal, R., Singh, B.R., Mwaseba, D.L., Kraybill, D., Hansen, D.O., and Eik, L.O. (2015). “Sustainable Intensification to Advance Food Security and Enhance Climate Resilience in Africa". Cham, Switzerland: Springer.

Li, X., Tong, L., Niu, J., Kang, S., Du, T., Li, S., and Ding, R. (2017). "Spatio-temporal distribution of irrigation water productivity and its driving factors for cereal crops in Hexi Corridor, Northwest China". Agric. Water Manage., 179, 55-63. doi: 10.1016/j.agwat.2016.07.010.

Liu, L., Wang, H., Dai, W., Lei, X., Yang, X., and Li, X. (2014). "Spatial variability of soil organic carbon in the forestlands of northeast China". J. Forest Res., 25(4), 867-876.

Munoz-Pardo, J., Ruelle, P., and Vauclin, M. (1990). "Spatial Variability of and Agricultural Field: Geostatistical Analysis of Soil Texture, Soil Moisture and Yield Components of Two Rainfed Crops”. Catena, 17, 369-381. 
Nayanaka, V.G.D., Vitharana, W.A.U., and Mapa, R.B. (2010). "Geostatistical analysis of soil properties to support spatial sampling in a paddy growing alfisol”. Tropical Agric. Res., 22(1), $34-44$.

Ngwira, A.R., Thierfelder, C., and Lambert, D.M. (2013). “Conservation agriculture systems for Malawian small holder farmers: long-term effects on crop productivity, profitability and soil quality". Renewable Agric. and Food Syst., 28(4), 350-63.

Robinson, T.P., and Metternicht, G. (2006). “Testing the performance of spatial interpolation techniques for mapping soil properties". Computers and Elect. in Agric., 50(2), 97-108.

Sanches, G.M., Graziano Magalhães, P.S., and Junqueira Franco, H.C. (2019). "Site-specific assessment of spatial and temporal variability of sugarcane yield related to soil attributes". Geoderma, 334, 90-98. doi: 10.1016/j.geoderma.2018.07.051.

Santra, P., Chopra, U.K., and Chakraborty, D. (2008). "Spatial variability of soil properties and its application in predicting surface map of hydraulic parameters in an agricultural farm”. Current Sci., 95 (7), 937-945.

Sharma, G.R., Maruthi Sankar, G.R., Akbari, K.N., Sreenivas Reddy, K., and Sutaria, G.S. (2014). Efficient tillage practice for maximum infiltration, rainwater use Efficiency, and profitability from groundnuts under semiarid Vertisols in western India. J. Irrig. Drain. Eng. (ASCE), 140 (3). DOI:10.1061/(ASCE)IR.1943-4774.0000681.

Shit, P.K., Bhunia, G.S., and Maiti, R. (2016). "Spatial analysis of soil properties using GIS based geostatistics models". Modeling Earth Systems and Environ., 2(2). doi: $10.1007 /$ s40808-016-0160-4.

Silva, J.C., Heldwein, A.B., Radons, S.Z., Maldaner, I.C.,Trentin, G., and Grimm, E.L. (2011). "Need for irrigation for beans in the central region of Rio Grande do Sul". Revista Brasileira de Engenharia Agricola e Ambiental, 15, 1030-1036. 
744

745

746

747

748

749

750

751

752

753

754

755

756

757

758

759

760

761

762

763

764

765

766

767

Usowicz, B., Hajnos, M., Sokolowska, Z., Józefaciuk, G., Bowanko, G., and Kossowski, J. (2004). "Spatial variability of physical and chemical soil properties in a field and commune scale". Acta Agrophysica, 103, 237-247

Vieira, V.A., Mello, C.R., and Lima, J.M. (2007). "Spatial variability of soil physical attributes in small watershed". Ciencia e Agrotecnologia, 31(5), 1477-1485.

Wackernagel, H. (1995). "Multivariate Geostatistic. An Introduction with Applications". Springer: Berlin/Heidelberg,Germany.

Wei, J.B., Xiao, D.N., Zeng, H., and Fu, Y.K. (2008). "Spatial variability of soil properties in relation to land use and topography in a typical small watershed of the black soil region, northeastern China”. Environ. Geology, 53(8), 1663-1672.

Weller, U., Castell, W.Z., Sommer, M., and Wehrhan, M. (2002). "Kriging and interpolation with radial base functions a case study". Soil Organic Carbon, 1-16.

Wigginton, J.D., Lockaby, B.G., Trettin, C.C., Nelson, E.A., Kolka, R.K., and Wisniewski, J. (2000). "Soil organic matter formation and sequestration across a forested flood plain chronosequence". In: Proceedings of Workshop held at Clemson University, 12-14 April 1999, pp 141-155.

Williams, A., Hunter, M.C., Kammerer, M., Kane, D.A., Jordan, N.R., and Mortensen, D.A. (2016). "Soil Water Holding Capacity Mitigates Downside Risk and Volatility in US Rainfed Maize: Time to Invest in Soil Organic Matter?". PLoS ONE, 11(8), 1-11. https://doi.org/10.1371/journal.pone.0160974.

Yates, S.R., Warrick, A.W., and Myers, D.E. (1986). "Disjunctive Kriging: 1. Overview of Estimation and Conditional Probability". Water Resources Res., 22(5), 615-621.

Zheng, Z., Zhang, F.R., and Ma, F.Y. (2009). "Spatio-temporal changes in soil salinity in a drip irrigated field”. Geoderma, 149, 243-248. 